\title{
Evaluation of the survivability of metallic elements in local damage given the beyond design basis effects
}

\author{
Elena Sorokina* and Anna Leonova \\ Department of Building Constructions, Kuban State Technological University, Moscovskaya 2, \\ Krasnodar, 350072 Russia
}

\begin{abstract}
The questions of ensuring the survivability of structural elements of buildings taking into account beyond-design effects, as well as the need to assess their loading under conditions of possible local damage are considered. This paper shows an energy algorithm for the study of physically nonlinear formulation of damaged objects, taking into account the features of finite element analysis of the bearing systems. The essence of the proposed approach is given by the example of a material point resting on a spring with nonlinear stiffness. The efficiency of this technique is tested on the example of a four-span beam. The method of determination on the basis of finite-element analysis of the maximum load of construction systems under beyond-design influences with regard to the physical nonlinearity of deformable objects is developed. The recommendations on the use of the given computational scheme in assessing the survivability of metal structural elements with possible local damage are given.
\end{abstract}

\section{Introduction}

While solving problems of ensuring the survivability of buildings with beyond design impacts taken into account it is obligatory to assess their loading in conditions of possible local destruction [1]. At that beyond design impacts may embrace natural and technogeneous impacts causing refuse and progressing structure failure.

The works [2-4] present strategies of such evaluations that do not imply detailed dynamic analysis of investigated objects. At that both calculations in Hookean formulation and with physically nonlinear material behavior taken into account were being studied.

The basis of these algorithm strategy is formed by the energetic approach by G.A. Geniev that uses stationary condition of absolute potential energy of a deformable object [2].

\footnotetext{
* Corresponding author: karpanina.elena@yandex.ru
} 


\section{Formulation of the problem}

The present work shows an algorithm for study of deformable objects in physically nonlinear formulation with peculiarities of finite-element analysis taken into account.

The essence of the suggested method may be explained on the example of the material point of mass $\mathrm{m}$, resting on the spring with nonlinear stiffness c (fig. 1). In the position $\mathrm{y}=\mathrm{y}_{0}>0$ the load is held by the buffer stop D. When the buffer stop is immediately removed, the load starts moving down.

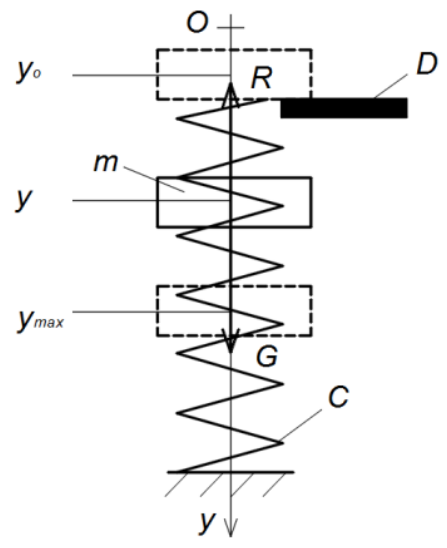

Fig. 1. Material Point on Spring.

The problem of determining the value $y=y_{\max }$ corresponding to extreme low load position is set.

\section{Theoretical part}

In the course of motion the mass point is affected by gravity force $\mathrm{G}$ and response $\mathrm{R}$ of the spring. At $\mathrm{y}=$ ymax load speed is equal to zero and the following condition should be met:

$$
\mathrm{A}_{\mathrm{g}}=-\mathrm{A}_{\mathrm{R}}
$$

where $A_{G}, A_{R}-$ work of forces $G$ and $R$ on the interval $y=\left[y_{0} ; y_{\max }\right]$.

$$
A_{G}=G\left(y_{\max }-y_{0}\right) ; A_{R}=\int_{y_{0}}^{y_{\max }} R_{y} d y
$$

where $\mathrm{Ry}$ - force projection $\mathrm{R}$ on the axis $\mathrm{Oy}$.

Assume that we can define the value $y$ at static spring loading with the auxiliary vertical force $\mathrm{P}$, which has the projection on the axis $\mathrm{y} \mathrm{P}_{\mathrm{y}}=\mathrm{P}_{0} \mathrm{a}$, where

$\mathrm{P}_{0}>0$ - invariable; $\mathrm{a} \geq 0$ - changing parameter. Taking equations into account (2) and accepting $\mathrm{R}=-\mathrm{P}_{\mathrm{y}}$, let us write:

$$
G\left(y_{\max }-y_{0}\right)=\int_{y_{0}}^{y_{\max }} P_{y} d y
$$

Having found solution to the formula (3) for $y_{\max }$, we define maximum spring loading in the result of immediate D basis removal. In the general case of construction systems loading analysis at sudden removal of certain connection we are going to set auxiliary loading in the form of the group of nodal forces applied to the finite-element model. Let us write the vector of these forces in the following form: 


$$
\mathrm{Q}=\mathrm{G}(1-\mathrm{a})+\mathrm{Tf}(\mathrm{a})
$$

where $\mathrm{G}$ - vector of gravity forces applied to nodes; $\mathrm{T}$ - force vector in eliminated connections of the source object loaded with forces $\mathrm{G} ; f(\mathrm{a})$ - function for which the following conditions are met: $f(0)=1$; at $0<\mathrm{a}<\mathrm{a}_{1}, f(\mathrm{a})>0$; at $\mathrm{a} \geq \mathrm{a}_{1} f(\mathrm{a})$, where $0<\mathrm{a}_{1}<1$.

Then at $\mathrm{a}=0$ loading of the object with remote connections $\mathrm{Q}$ reproduces stress strain behavior of the source system. It is necessary to find the value $a=a_{a m a x}$, at which work $A_{Q}$ of forces $Q$ will be equal to work $A_{G}$ of forces $G$. Here the following correspondences are fair:

$$
\mathrm{A}_{\mathrm{Q}}=\int_{0}^{\mathrm{a}} \mathrm{Q}^{\mathrm{T}} \mathrm{d} \delta_{\mathrm{Q}} ; \quad \mathrm{A}_{\mathrm{G}}=\mathrm{G}^{\mathrm{T}} \delta_{\mathrm{G}}
$$

where $\delta_{\mathrm{Q}} \delta_{\mathrm{G}^{-}}$vectors of generalized node motions corresponding to forces $\mathrm{Q}$ and $\mathrm{G}$.

Then in calculations we accepted $\mathrm{a}_{1}=0,1 ;$ at $0 \leq \mathrm{a} \leq 0,1$ we set $f(\mathrm{a})=1-10 \mathrm{a}$.

Let us check the effectiveness of the given strategy on the example of the four span beam shown in figure 2 .

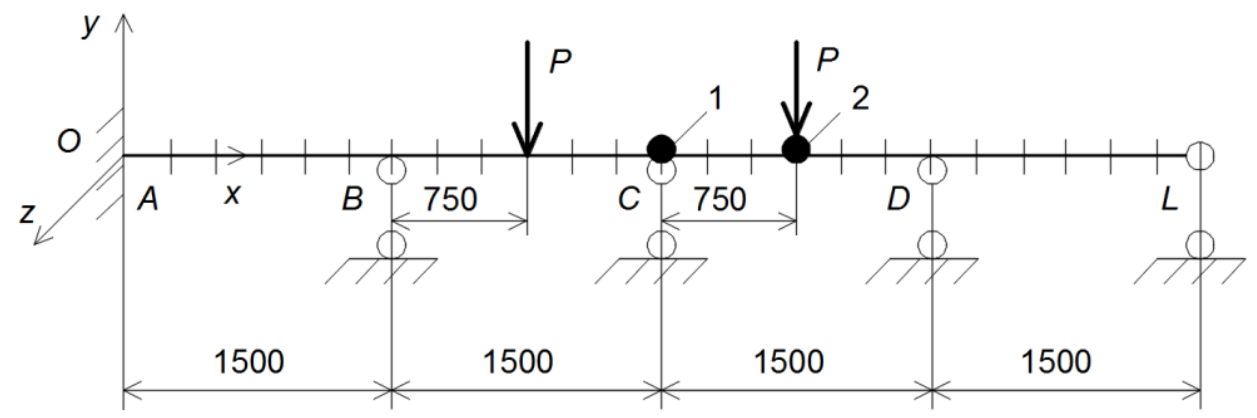

Fig. 2. Continuous Steel Beam under Effect of Two Concentrated Forces P: 1, 2- Plastic Hinges.

\section{Practical importance}

The beam is made of I-beam No.30 GOST 8239-89. The main I-beam surface with maximum bending stiffness is placed vertically. The material of the beam is structural steel with modulus of rigidity $\mathrm{E}=2,1 * 105 \mathrm{MPa}$. We studied beam loading with gravity forces $\mathrm{P}=318 \mathrm{kN}$ from attached loads. In this work [3] there are calculations of this beam in dynamic formulation for the case of immediate elimination of the basis D.

On figure 2 strokes show the introduced separation of the beam on finite elements.

In intercell connection envisaged the possibility of formation of plastic hinges at achieving the maximum momentum $\mathrm{M}_{\max }=\mathrm{W}_{\max }$ б, где $\mathrm{W}_{\max }-$ maximum moment resistance at bending. For I-bean we accepted $\mathrm{W}=1.15 \mathrm{~W}_{\mathrm{z}}$, where $\mathrm{W}_{\mathrm{z}}-$ section moment resistance at bending relative to the axis $\mathrm{z}$. At that $\mathrm{M}_{\max }=135.7 \mathrm{kNm}$.

It was supposed that on parts of the pin between plastic hinges the material work on the linear-elastic stage and for each plastic hinge there is a scheme of ideal elastic plastic deformation.

At the $\mathrm{P}$ value under consideration the plastic hinge was formed in the section above the basis $\mathrm{C}$, then - in the central section of the part CD.

In the give work while evaluating the $\alpha_{\max }$ value we held calculations for the beam at static force condition $\mathrm{Q}$ taking into account the possibility of plastic hinges formation in the same sections and at the same value $\mathrm{M}_{\max }$. During formation of the vector $\mathrm{G}$ only $\mathrm{P}$ forces were taken into account.

Figure 3 shows graphs of correspondences $\mathrm{A}_{\mathrm{Q}}$ and $\mathrm{A}_{\mathrm{G}}$ from a. 


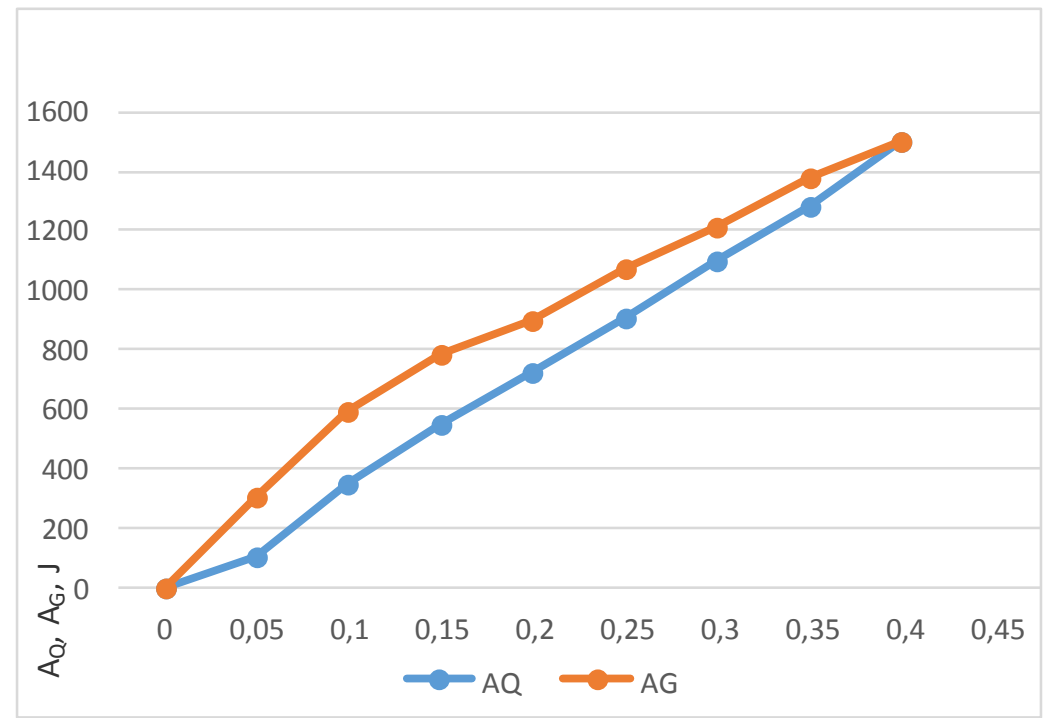

Fig. 3. Correspondences of Work of Forces $\mathrm{G}$ and $\mathrm{Q}$ from $\alpha$ for Steel Beam.

The value $\mathrm{a}_{\max }=0.40$ is set. Figure 4 compares deformable beam schemes at $\mathrm{a}=\mathrm{a}_{\max }$, where $\mathrm{v}$ - projection of transition to the axis $\mathrm{y}$ obtained with a help of suggested approximate strategy and in dynamic analysis[4].

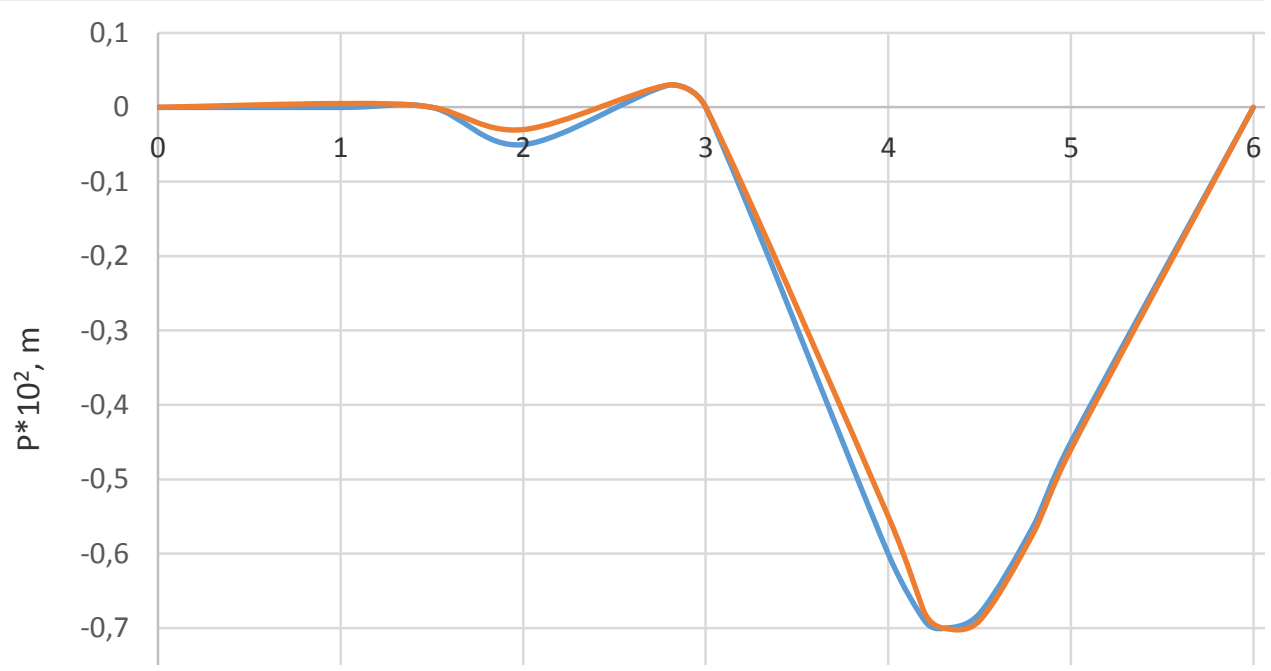

Fig. 4. Vertical Motion in Steel Beam: 1 - Energetic Approach; 2 - Calculation in Dynamic Formulation.

Figure 4 shows that the energetic approach under consideration allowed to receive evaluation of maximum beam bending that was precise enough.

\section{Conclusion}

Thus on the basis of finite-element analysis we developed a strategy of defining maximum loading of construction systems at beyond design impacts with physical nonlinear character 
of deformable objects taken into account. The given calculating scheme may be used for evaluating survivability of metallic elements at possible local destruction [5].

\section{References}

1. Kolchunov V.I. General development directions of construction solutions and ensuring physical security [Text] / V.I. Kolchunov // Industrial and Civil Contruction. - 2007. No.10. - 12-13 pp.

2. Geniev G.A. Durability and deformability of reinforced concrete structures at beyond design impacts [Text] / G.A. Geniev, V.I. Kolchunov, N.V. Klyueva, A.I. Nikulin, K.P. Pyatikretovsky. - M: ASV, 2004. - 2016 p.

3. Klyueva N.V. On evaluation of survivability of reinforced concrete frame construction systems at sudden beyond design impacts / N.V. Klyueva, O.A. Vetrova // Industrial and Civil Contruction. - 2006. - No.11. - 56-57 pp.

4. Veryuzhky Yu.V. Methods ofreinforced concrete mechanics [Text] / Yu.V. Veryuzhsky, V.I. Kolchunov. - K.: Knizhkove vid-vo NAU, 2005. - 653 p.

5. Karpanina E.N. Certain issues of ensuring survivability of buildings with beyond design impacts taken into account // Science time No.5(29) 2016 275-279 pp.

6. Shulga S.N. A method for estimating survivability and determining the remaining resource of cranial-subcranial trusses with fracture-like defects / Science and Security No.4, December 2014

7. Travush VI, Kolchunov VI Klyueva N.V. Some directions in the development of the theory of survivability of structural systems of buildings and structures // Industrial and Civil Construction No. 32015

8. Klyueva NV, Korenkov PA Technique of experimental determination of survivability parameters of reinforced concrete frame-rod structural systems // Industrial and Civil Construction No. 2, 2016

9. Travush VI Fedorova N.V. Calculation of the survivability parameter of frame-rod structural systems // Scientific Journal of Construction and Architecture No. 1 (45) 2017

10. Chen J., Huang Õ., Ma R., He M. // Experimental study of the resistance of a two-story steel frame to progressive destruction // Journal of Performance of Constructed Facilities . 2012. No.5. Vol. 26. Pp. 567-575.

11. Kuhlmann U., Roelle L., Izzuddin B. A. Resistance and response of steel and steelconcrete composite structures in the progressive collapse assessment // Structural Engineering International. 2012. ${ }^{1}$. Vol. 22. Pp. 86-92.

12. Klyueva N. In. Bukhtiyarova A. S., Androsova N. B. To the analysis of researches of survivability of constructive systems at beyond design influences/ Construction and reconstruction No. 4, 2009, Page. 15-21.

13. Klyueva N. In, Tamrazyan A. G. Fundamental properties of structural systems that reduce the risk of failure of building elements/ Proceedings of the southwest state University No. 5-2, 2012, p. 126-131.

14. Berzinski J. A., Burzynska L. P. Reserves the survivability of a bezrigelny framework during design basis impact/Earthquake-resistant construction. safety of buildings No. 3, 2013. with Tr. 31-35.

15. Bukhtiyarova, A. S., Col. And. Rybakov D. A., Filatova S. A. a Study of the survivability of residential and public buildings with new constructive system of industrial panel and frame elements/ Construction and reconstruction, No. 62014 pp. 18-24.

16.Zhang, C.Song, Z.,Liu Z.Yang, C.Cheng, Q.Liu, M. Tribological properties of flexspline materials regulated by micro-metallographic structure/Tribology International Volume 127, 2018, Pages 177-186. 
17. Dai, L.-H., Wu, C., An, F.-J., Liao, S.-S. Experimental Investigation of PolyureaCoated Steel Plates at Underwater Explosive Loading/Advances in Materials Science and Engineering volume 2018, 2018, No.1264276.

18. Vitu, L., Laforge, N., Malécot, P.,Boudeau, N., Manov, S., Milesi, M. Characterization of zinc alloy by sheet bulging test with analytical models and digital image correlation/AIP Conference ProceedingsVolume 1960, 2 May 2018, No. 15001521st International ESAFORM Conference on Material Forming, ESAFORM 2018; Palermo; Italy; 23 April 2018 to 25 April 2018; Code 136352. 